\title{
Use of a dynamic method in calibration of dye-dilution curves during cardiac surgery ${ }^{1}$
}

\author{
Yen T. Lin, David H. Atkin, and Yasu Oka \\ From the Department of Anesthesiology, Albert Einstein College of Medicine, Bronx, New York, U.S.A
}

A simplified dynamic method of calibration for dye-dilution curves is described. The method involves appropriate matching of the fluid volume in the mixing chamber, the blood withdrawal rate, and the calibration dose of dye. It was used to compare the observed versus calibrated pump output of a heart-lung machine with individual dye-dilution curves obtained from 15 patients during total cardiopulmonary bypass. The results indicate that the difference (range $+14 \%$ to $-8 \%$ ) between the two is statistically insignificant. The method is rapid and relatively simple. It is particularly useful for cardiac output determination during unsteady clinical conditions because of the ability to calibrate dye curves at the time they are recorded.

Measurement of cardiac output from dye-dilution curves requires a calibration procedure relating points on the curve to known blood concentrations of the dye. The serial dilution method of calibration is cumbersome and time consuming. It entails repeated pipetting of blood for mixing with dye. Under unsteady clinical conditions such as cardiac surgery, or haemorrhagic shock, gross changes in blood composition are common and only repeated calibrations will assure the accuracy of cardiac output determinations. A simple, rapid, and accurate calibration procedure is necessary; one which permits reinfusion of the blood used has an added advantage.

Sparling et al. (1960) described a simple and time-saving dynamic method for calibrating dyedilution curves. They compared the area of the dilution curve obtained from the patient with that derived from a small calibration system built into the sampling line. Since then several studies of the dynamic method have been published (Emanuel and Norman, 1963; Emanuel et al., 1966; Hamer et al., 1966; Shinebourne, Fleming, and Hamer, 1967; Sparling et al., 1960). Its accuracy and reproducibility have been confirmed by direct comparison of the calibration factor of this method with that of the standard serial-dilution method (Völlm and Rolett, 1969). However, when applying the

Received 18 November 1974 .

${ }^{1}$ This investigation was supported in part by a Research Grant from the Upjohn Company. Dr. Yasu Oka is a recipient of a Research Grant from the Upjohn Company. technique as described by Sparling et al. (1960), and Emanuel and Norman (1963) during cardiac surgery, we encountered numerous difficulties, especially with regard to injection of the calibration dose and the amount of blood required for the procedure. Therefore, through a series of experiments, we changed the technique to make it more suitable for clinical applications.

The experiment described here is designed to validate the accuracy of this method by comparing simultaneously the dye-dilution output using this method of calibration with the pump output from a cardiopulmonary bypass machine.

Methods
Calibration system
The system used is shown schematically in Fig. I.
Upstream from the cuvette densitometer (C), a short
piece of heavy Latex tubing (taken from an intravenous
infusion set) served as the injection chamber (A). Be-
tween the injection chamber and the densitometer, a
mixing chamber (B) was connected. This chamber was
made of Silastic tubing (Dow Corning) 5 cm long and
6 mm inner diameter, filled with glass beads of 2 mm
diameter, and with 'teflon' mesh at each end to prevent
impaction of glass beads during aspiration. Each end is
then sealed with a male adaptor leaving a fluid volume
of o.6 ml in the chamber. A Gilson (DTL) cuvette
densitometer (C) with a GDI-8 DC amplifier was used
as the sensing unit. This unit has a linearizing circuit to
maintain linearity within the range of dye concentration
encountered in the study. The amplifier output was




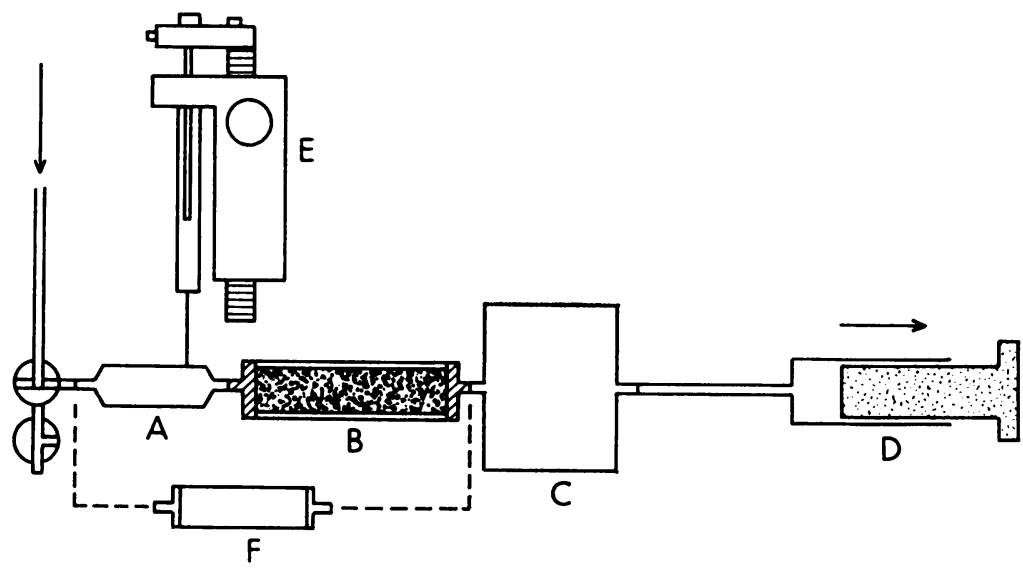

FIG. I Schematic representation of system for dynamic calibration. A=injection chamber; $B=$ mixing chamber; $C=$ densitometer; $D=$ withdrawal pump; $E=$ Hamilton microlitre syringe and repeating dispenser; $F=$ Luer adaptor.

simultaneously displayed on an oscilloscope and recorded on paper (Rapid-Writer - Electronics for Medicine). Downstream from the cuvette, an intravenous extension tube (Portex) was used to connect the cuvette and a $50 \mathrm{ml}$ glass syringe on the Harvard pump (D), which was calibrated to withdraw blood at a constant rate of $16 \mathrm{ml} / \mathrm{min}$.

Indocyanine green (Cardio-Green) dye in a concentration of $2.5 \mathrm{mg} / \mathrm{ml}$ was used as the indicator. The dye solution was prepared for each patient by dissolving $50 \mathrm{mg}$ indocyanine green in $20 \mathrm{ml}$ distilled water. The test dose $(2 \mu \mathrm{l})$ was injected into the chamber (A) through a $25 \mathrm{G}$ needle with a Hamilton No. 710 microlitre syringe mounted on a Hamilton repeating dispenser (E).

The entire system was sterile before each use and was maintained with sterile technique during use. Parts of the system were disposable (cannula, stopcocks, intravenous infusion tubing). The remaining parts were cleaned after use and resterilized either by ethylene oxide (parts A, B, C, E, F) or by autoclaving ( $50 \mathrm{ml}$ glass syringe).

\section{Dynamic calibration}

The system was flushed with heparinized saline $(20000$ units added to a litre of normal saline) to purge the air. Then arterial blood was withdrawn at the constant rate (16 $\mathrm{ml} / \mathrm{min}$ ) and the densitometer balanced at zero deflection. The needle was introduced into the injection chamber and the densitometer was set to the sensitivity previously determined to result in a peak deflection of the calibration curve of about $100 \mathrm{~mm}$ on the recording paper. Dye solution, $2 \mu \mathrm{l}$, was injected and the curve was observed and recorded. When the deflection returned to zero the injection was repeated. Five to eight calibration curves were thus obtained in succession. After the last calibration curve, the withdrawal system was again flushed with heparinized saline.

\section{Pump output curves}

Fifteen adult patients having either aortic or mitral valve replacement or aortocoronary venous graft under total cardiopulmonary bypass were subjects for this study.

The procedures were explained to the patients and consent for the study obtained the day before surgery. In the operating room the radial artery was cannulated percutaneously using a 'teflon' catheter (Deseret, I8G) $5 \mathrm{~cm}$ long and $0.8 \mathrm{~cm}$ inner diameter.

The patients were anaesthetized either with halothane or with morphine sulphate. All patients received the same diameter aortic cannula and the same pump machine was used. The pump output was calibrated previously. All bypasses were carried out under normothermia. After the establishment of stable total cardiopulmonary bypass, the calibration curves were obtained, followed immediately by the dye-dilution curves from the patient. Such curves were obtained in duplicate in each patient by injecting I to $2 \mathrm{ml}$ dye solution into the arterial tubing distal to the rotary pump and immediately proximal to the arterial line filter. The injection port stopcock had its dead space previously filled with dye solution. Blood was withdrawn at the rate of $16 \mathrm{ml} /$ min from the radial artery through the densitometer with a male-to-male luer adaptor $(F)$ in place of parts $A$ and $B$.

\section{Calculation of flow}

The pump flow into the aorta was calculated according to equation (I) (Sparling et al., 1960):

$$
Q=\left(I \times Q_{c} \times A_{c}\right) /\left(I_{0} \times A\right)
$$

where $I$ is the amount of indocyanine green injected for the pump output curves, $I_{0}(\mu l)$ is the amount injected for the calibration curves, $Q_{c}$ is the withdrawal rate ( $16 \mathrm{ml} / \mathrm{min}$ ), and $A_{o}$ is the mean area under the calibration curves (planimetrically determined). The first calibration curve of each series was discarded. The 


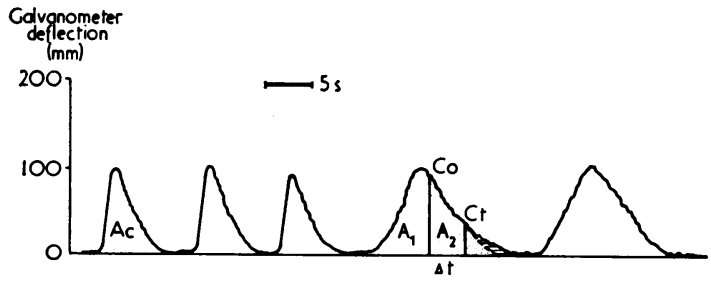

FIG. 2 Diagram of calibration curves and dyedilution curves. For explanation of symbols, see text.

arithmetic mean of the remaining four to seven curves was used in the computations. $A$ is the area under the pump output curves. This was analysed according to the method described by Cohn and Del Guercio (I966), in which the forward area of the curve $A_{1}$ was planimetrically determined. $A_{2}$ is the area under the exponential portion of the downslope, excluding recirculation (Fig. 2).

$$
A=A_{1}+A_{2}
$$

The downslope of the curve was scanned with the aid of a computer (Olivetti $\mathrm{P602}$ ) which was programmed to choose two points within exponential portion of the curve.

The deflection of these two points $\left(C_{o}\right.$ and $\left.C_{t}\right) 3$ to 5 seconds apart $(\Delta t)$ on the downslope of the curve was obtained and $\mathrm{A}_{2}$ calculated according to equation (3).

$$
A_{2}=-C_{o} \times \Delta t / \log _{\ominus} C_{t} / C_{o}
$$

The computer was programmed to solve for pump output as given by equation (4).

$$
\mathrm{Q}=\frac{\mathrm{I} \times \mathrm{Q}_{\mathrm{c}} \times \mathrm{A}_{\mathrm{c}}}{\mathrm{I}_{\mathrm{c}} \times\left[\mathrm{A}_{1}-\left(\mathrm{C}_{\mathrm{o}} \times \Delta \mathrm{t}\right) / \log _{\mathrm{e}} \mathrm{C}_{\mathrm{t}} / \mathrm{C}_{\mathrm{o}}\right]}
$$

in which, $I_{0}(2.0 \mu \mathrm{l})$ and $Q_{c}(16 \mathrm{ml} / \mathrm{min})$ are constant.

\section{Results}

The reproducibility of the dynamic calibration technique was analysed in the 15 experiments. Seventy-three calibration dye curves were acceptable. The first calibration curve of each series was significantly smaller in area than the remaining curves and was discarded. Four additional curves were discarded because of gross distortions caused by accidental air leak into the withdrawal system, obstruction of the withdrawal system, or faulty injection of the test dose. The mean curve areas, standard deviation, and the coefficient of variance are listed in Table $\mathrm{I}$.

In 13 of the 15 series, the calibration curve area had adequate reproducibility (CV within $\pm 5 \%$ ). In all I5 studies, the calculated outputs were obtained in duplicate, and the arithmetic mean of the two outputs was used to compare with the indicated pump output (Table 2, Fig. 3).

The paired t-test was used to test for differences
TABLE I Variance of curve areas in 15 series of calibration dye curves

\begin{tabular}{rllrl}
\hline Case No. & $\begin{array}{l}\text { No. of } \\
\text { dye } \\
\text { curves }\end{array}$ & $\bar{A}_{\mathrm{c}}$ & $S D$ & $C V(\%)$ \\
\hline I & 4 & I70.8 & 7.6 & \\
2 & 6 & 220.8 & 9.4 & 4.4 \\
3 & 6 & 203.2 & 7.2 & 3.1 \\
4 & 6 & 216.3 & 7.8 & 3.6 \\
5 & 6 & 250.2 & 9.3 & 3.7 \\
6 & 5 & 340.8 & 12.1 & 3.5 \\
7 & 4 & 302.3 & 23.2 & 7.7 \\
8 & 4 & 211.3 & 6.6 & 3.1 \\
9 & 5 & 205.8 & 13.8 & 6.7 \\
I0 & 4 & 111.3 & 4.7 & 4.2 \\
II & 6 & 126.7 & 5.0 & 3.9 \\
I2 & 6 & 176.7 & 6.3 & 3.5 \\
I3 & 4 & 151.5 & 5.3 & 3.5 \\
I4 & 3 & 149.3 & 7.4 & 4.9 \\
I5 & 4 & 103.3 & 2.2 & 2.1 \\
\hline
\end{tabular}

$\overline{\mathrm{A}}_{\mathrm{c}}=$ mean curve area; $\mathrm{SD}=$ standard deviation; $\mathrm{CV}(\%)=$ coefficient of variance.

between the calculated value and the pump output. The test does not indicate a statistically significant difference $(t=0.60 ; P>0 . I)$. The regression equation was $y=1.013 x-0.016$. It was essentially the same if the regression line were drawn through the origin. The estimates of the correlation coefficient

TABLE 2 Comparison of calculated output and pump output from heart lung machine in 15 experiments during cardiopulmonary bypass

\begin{tabular}{lllll}
\hline $\begin{array}{l}\text { Case } \\
\text { No. }\end{array}$ & Operation & $\begin{array}{l}\text { Calcu- } \\
\text { lated } \\
\text { output } \\
\text { (l/min) }\end{array}$ & $\begin{array}{l}\text { Pump } \\
\text { output } \\
(l / m i n)\end{array}$ & $d(\%)$ \\
& & 4.57 & 4.00 & +14.3 \\
\hline I & Aortocoronary bypass & & \\
2 & Aortic valve replacement & 4.09 & 4.20 & -2.6 \\
3 & Aortic valve replacement & 3.87 & 4.00 & -3.3 \\
4 & Aortocoronary bypass & 3.95 & 3.88 & +1.8 \\
5 & Aortic valve replacement & 2.95 & 3.20 & -7.8 \\
6 & Aortic valve replacement & 4.30 & 4.40 & -2.3 \\
7 & Aortocoronary bypass & 5.24 & 5.00 & +4.8 \\
8 & Mitral valve replacement & 4.26 & 4.20 & +1.4 \\
9 & Aortocoronary bypass & 4.39 & 4.40 & -0.2 \\
I0 & Mitral valve replacement & 4.12 & 4.28 & -3.7 \\
II & Mitral valve replacement & 4.79 & 4.32 & +10.9 \\
I2 & Aortocoronary bypass & 4.72 & 5.15 & -8.4 \\
I3 & Aortocoronary bypass & 5.15 & 4.86 & +6.0 \\
I4 & Aortocoronary bypass & 4.93 & 4.60 & +7.0 \\
I5 & Aortic valve replacement & 4.59 & 4.80 & -4.4 \\
\hline$\overline{\mathrm{d}}=0.04$ & sd $=0.07$ & $\mathrm{t}=0.60$ & $\mathrm{P}>0.10$ & \\
\hline
\end{tabular}

$d=$ difference as a per cent of pump output; $\bar{d}=$ mean difference; $s \bar{d}=$ standard error of the mean difference. 


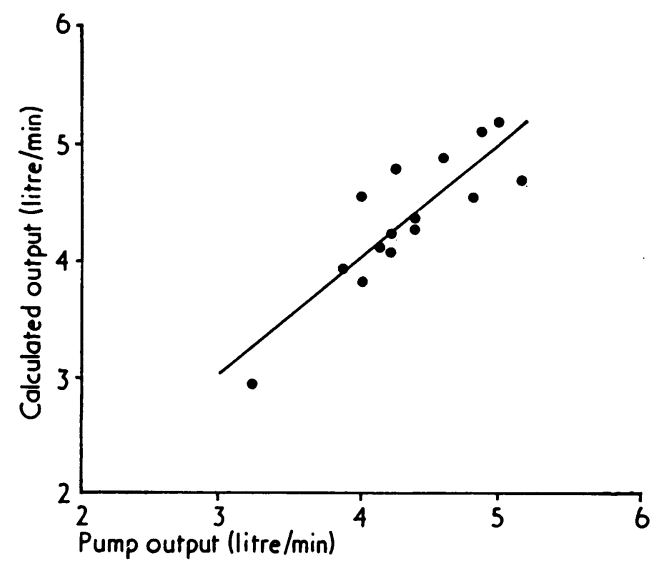

FIG. 3 Fifteen comparisons of the calculated output in $\mathrm{l} / \mathrm{min}$, using dynamic method of calibration and fixed pump output in l/min from the heart lung machine. Regression equation: $y=1.013 x-0.016$.

both parametrically and non-parametrically revealed that both were significantly different from zero ( $r=0.87$ and 0.84 , respectively).

\section{Discussion}

The first calibration curve of each series was discarded because it was found to be consistently smaller than the subsequent curves. No mention of this problem has been made by previous investigators. We have not determined the reason but several factors may contribute. (I) A portion of the first calibration dose may be removed by some physical combination with blood protein newly adsorbed onto surfaces in the mixing chamber. Subsequent doses in the same series may not be affected because of the apparent saturation of these binding sites during the first passage of dye. At the end of the series the heparinized saline washes out the binding protein and the entire process will be repeated with the next initial calibration. (2) Some of the dye may be directly bound to surfaces in the system, or (3) introduction of the needle into the injection chamber causes the first calibration dose to be smaller than $2 \mu$ l. The latter two reasons are doubtful explanations. We experimented by injecting several $2 \mu l$ doses of dye into the chamber during the initial saline purge of air and found that this did not prevent the reduction in area of the first calibration curve that followed.

Other factors influencing the reproducibility of curve areas are the precision of test dose injection, constancy of withdrawal rate, stability, and linearity of the densitometer-recorder system, and the pre- cision of planimetry. The reproducibility of our calibration method is demonstrated by measurements of coefficients of variance of curve area for each series (Table I). All but 2 of the 15 series had coefficients of variance less than 5 per cent. As described, our method suffers an acceptably small random error. Similar random errors have been found by Hamer et al. (1966).

To demonstrate the applicability and accuracy of the method, the pump output was measured by dye-dilution method during total cardiopulmonary bypass. As suggested by Völlm and Rolett (1969), each recording of output curves was immediately preceded by the calibration. The dose of dye was chosen so that the peak deflection of the output curves and calibration curves was similar. The variation observed in the areas of calibration curves among the patients was caused by different settings in the sensitivity of recordings, which was adjusted according to the peak deflection of the curves at the beginning of the recordings. The range of outputs we studied is relatively narrow $(3.2 \mathrm{l} / \mathrm{min}$ to 5.2 $1 / \mathrm{min})$. The dye-dilution method of cardiac output determination may suffer a major error from early recirculation at very low flows (Oriol, Sekelj, and McGregor, 1967). Scanning the downslope of the curves with a computer to select the exponential portion of the curves helps to reduce but not eliminate such errors. At high flows there could be problems caused by spectral shifts in the concentrated dye injected (Saunders et al., 1970), therefore, one should properly choose the dose of dye and watch the appearance time of the curves.

The dynamic method for calibrating dye-dilution curves has major advantages over the serial-dilution method. Appropriate matching of the fluid volume in the mixing chamber, the blood withdrawal rate, and the calibration dose of dye, together with the use of a repeating dispenser for injection enables us to obtain a series of calibration curves requiring less than $20 \mathrm{ml}$ of the patient's blood and 2 minutes of time. The aspirated blood remains sterile and with filtration may be immediately reinfused into the patient. This saving may be very significant in children or in any patient subjected to many cardiac output determinations. Fox and Wood (1960) found no significant change in optical density of a $\mathrm{r} \mathrm{mg} / \mathrm{l}$ solution of dye in blood from variations in $p \mathrm{H}$, electrolyte concentrations, temperature, or protein concentration within physiological ranges. However, additive effects of several such changes could be significant. During cardiac surgery, rapid changes in blood constituents and temperature occur. In addition, over the course of several hours, errors could be introduced by changes in the light absorption by dye caused by deterioration, and in 
the sensitivity of the densitometer-recorder system. Therefore, premeasurement calibration should improve the accuracy of cardiac output determinations under unsteady clinical conditions. The ease of performance of the dynamic method and the opportunity for minimizing blood loss facilitate frequent calibrations. Other advantages of this method include compensation for non-linearities of the densitometer-recorder system (Shinebourne et al., 1967) and the suitability for on-line computer computation of cardiac output (Hamer et al., 1966).

After documenting the accuracy of the method, we have applied it satisfactorily in numerous clinical measurements of cardiac output. The materials needed are widely available and are easily assembled, and the procedures can be mastered with little effort. We recommend that others adopt this as the preferred method of calibration in clinical situations already outlined.

The authors are indebted to Dr. Robert W. M. Frater, and Dr. Louis R. Orkin, for the co-operation and help extended to us during this study.

\section{References}

Cohn, J. D., and Del Guercio, L. R. M. (1966). Nomogram for the rapid calculation of cardiac output at the bedside. Annals of Surgery, 164, ro9.

Emanuel, R., Hamer, J., Chiang, B.-N., Norman, J., and Manders, J. (1966). A dynamic method for the calibration of dye dilution curves in a physiological system. British Heart fournal, 28, 143.

Emanuel, R., and Norman, J. (1963). Evaluation of a dynamic method for calibration of dye dilution curves. British Heart fournal, 25, 308.

Fox, I. J., and Wood, E. H. (1960). Indocyanine green: physical and physiologic properties. Proceedings of the Staff Meeting of the Mayo Clinic, 35, 732.

Hamer, J., Emanuel, R., Norman, J., and Burgess, M. (1966). Use of a computer in the calibration of dye dilution curves by a dynamic method. British Heart fournal, 28 , 147.

Oriol, A., Sekelj, P., and McGregor, M. (1967). Limitations of indicator-dilution methods in experimental shock. Journal of Applied Physiology, 23, 605.

Saunders, K. B., Hoffman, J. I. E., Noble, M. I. M., and Domenech, R. J. (1970). A source of error in measuring flow with indocyanine green. Fournal of Applied Physio$\log y, 28,190$.

Shinebourne, E., Fleming, J., and Hamer, J. (1967). Calibration of indicator dilution curves in man by the dynamic method. British Heart fournal, 29, 920.

Sparling, C. M., Mook, G. A., Nieveen, J., Van der Slikke, L. B., and Zijlstra, W. G. (1960). Calibration of dye dilution curves for calculating cardiac output and central blood volume. In Proceedings of the 3 rd European Congress of Cardiology, Rome, Vol. 2, pp. 595-598. Excerpta Medica Foundation, Amsterdam.

Völlm, K. R., and Rolett, E. L. (1969). Calibration of dye dilution curves by a dynamic method. fournal of Applied Physiology, 26, I47.

Requests for reprints to Dr. Yen T. Lin, Department of Anesthesiology, Albert Einstein College of Medicine, 1300 Morris Park Avenue, Bronx, New York 1046I, U.S.A. 